\title{
EducaÇÃo e psicanálise em AdoRno - A (RE)VERSÃo APOLOGÉTICA DA CULTURA*
}

\author{
Sílvia Rosa da Silva Zanolla \\ Universidade Federal de Goiás, Goiânia, Goiás, Brasil
}

\begin{abstract}
Resumo: O objetivo deste trabalho é analisar a complexa relação entre a Educação e a Psicanálise à luz da teoria crítica adorniana. $O$ debate se pauta, epistemologicamente, pelos conceitos de sujeito e objeto, materialismo e idealismo, subjetividade e objetividade. A proposta considera contribuições de importantes pensadores da teoria do conhecimento, como Kant, Marx e Freud, na interface com a cultura e a educação. Estabelecem-se como discussão pertinente ao objeto os conceitos-chave: crítica, autocrítica, consciência, autonomia e humanização.
\end{abstract}

Palavras-chave: Educação. Psicanálise. Teoria crítica. Teoria adorniana.

AUTORES IMPRESCINDÍVEIS À CONSTITUIÇÃO DA TEORIA CRÍTICA FRANKFURTIANA, SOBRETUdo FreUd e MarX

Qualquer estudioso que tenha se debruçado, com seriedade, sobre o objeto da teoria crítica frankfurtiana haverá de admitir sua complexidade, devido a significados variados a ela atribuídos, sobretudo quando se trata de compreender um de seus mais importantes autores: Theodor Adorno. Por princípio epistemológico, de acordo com a teoria do conhecimento, a crítica adorniana não se permite captar pela mera formalização metodológica, embora dessa não decline. De nossa parte, o debate percorrerá o arcabouço teórico de Adorno, concentrado em duas áreas específicas do conhecimento: Educação e Psicanálise.

A Educação possui perspectiva ampla em Adorno (1999); requer, antes de um aprofundamento conceitual, que se apresentem bases epistemológicas que a consolidam, sobretudo, considerando três autores

* Artigo recebido em 13/6/2013 e aprovado em 30/9/2013. 
imprescindíveis à constituição da teoria crítica frankfurtiana: Kant, Freud e Marx. Não obstante, é preciso esclarecer que o foco dessa discussão gira em torno de uma questão primordial que mobiliza a atenção de Horkheimer e Adorno, apresentada no Prefácio da obra Dialética do esclarecimento; trata-se de "Tentar descobrir por que a humanidade, em vez de entrar em um estado verdadeiramente humano, está se afundando em uma nova espécie de barbárie" (HORKHEIMER; ADORNO, 1985, p. 11).

Esse dilema constitui um princípio para a obra adorniana, independente das temáticas com as quais se debateu: atividades artísticas ligadas à literatura, música, cinema, teatro e pesquisas voltadas à cultura, educação e sociedade em geral. Seu olhar deixa escapar, nas obras, uma indagação ligada ao sentido humanista do indivíduo e da sociedade: O que confere ao homem estatuto de ser social, de modo a se autorizar reconhecer e ser reconhecido como humano no mundo dito civilizado? Com esse dilema, justifica-se a apresentação do pensamento kantiano como uma das principais bases teóricas que possibilitam compreender, em Adorno, a relação entre psicanálise, educação e teoria crítica frankfurtiana (ZANOLLA, 2007).

Kant, herdeiro do pensamento humanista, é um filósofo mal compreendido e de complexa leitura - por isso, pouco lido na fonte -, o que faz com que haja equívocos sobre suas ideias não apenas na área da educação como também na filosofia em geral (PASCAL, 1999). Dentre outros, é importante avaliar dois aspectos para compreender a educação na perspectiva kantiana: a essência indeterminada do ser e a faculdade da maioridade como possibilidade formativa.

A essência indeterminada do ser reproduz certa ideia apriorística do objeto, o que possibilita pensar a formação. Isso consiste que no reconhecimento entre sujeito e objeto; a formação em movimento rege a vida e a sociedade do ponto de vista teórico e prático. A educação é substrato do complexo processo tecido pelas possibilidades objetivas e subjetivas, apresentadas como pressuposto do que se entende por conhecimento. Isso pode ajudar a explicar, por exemplo, porque intenções formativas convertemse em ações que configuram a dominação e a barbárie denunciadas por Adorno (1999). Desse modo, o objeto possui uma (in)dependência que precede à relação com o objeto. Daí o fato de a alienação ser um elemento presente na sociedade. $O$ ideal estado que consolida a educação e a cultura não garante a formação humana, embora a persiga.

Assim, quanto mais desprovida do caráter reflexivo e crítico, maior a idealização da própria intencionalidade; como emblema, tem-se a apologia ao conceito de mediação enquanto elemento formativo, a partir de formulações tais como de Vigotski sobre a zona de desenvolvimento proximal (ZDP), 
funções superiores e a atividade; categorias sócio-históricas da aprendizagem, desprovidas de olhar crítico, fetichizam a própria práxis pedagógica (ZANOLLA, 2002; 2007; 2012).

Por esse raciocínio, a arte como conhecimento, de maneira imanente, é atividade cara, inegável aliada da educação. Isso porque o sentido estético da educação é perpassado pela imagem que o homem constrói de si e do social pelo trabalho, sua capacidade de transformar a natureza tendo como base seus valores apreendidos, faculdades adquiridas e elaboradas, categorias de entendimento, capacidade de elaborar juízos frente à demanda da prática que agrega juízo sintético e juízo analítico: isso funda a ideia do a priori para o filósofo Kant (MASSARO, 1980).

Para Kant (2003), não existe o radical predomínio sócio-histórico nas ações humanas, pelo fato de que o mundo inteligível e sensível do homem é complexo e não se deixa aprisionar pelo "ver de imediato o objeto", o que poderia condicionar o pensar determinista. $\mathrm{O}$ autor alerta que em nome da crítica ao empirismo pode-se reduzir o conhecimento ao pensamento dogmático. Nesse sentido, não há experiência mais tecnicista do que o pensamento pragmático, assim como não há nada mais idealista do que a prática abstrata.

Conforme exposto, outro ponto importante para pensar a educação em Kant diz respeito à faculdade ou conceito de "maioridade". As ideias kantianas visam o pensar através da "lupa" do autorreconhecimento do mundo interno, sensível, almejando o sujeito da maioridade, emancipado. Desse modo, contra a conformação advinda dos processos deformativos da menoridade e da dependência que alimentam a dominação, apresenta-se a formação crítica para a autonomia (ADORNO, 1999).

Isso se reflete em sua obra, por exemplo, no livro Crítica da razão pura (KANT, 2003) Não aparece aí apenas a defesa da razão ideal, como elemento relativo e indissociável de contradição, mas, ao contrário, a razão pura apresenta duplo sentido: de um lado, postula a crítica "à própria razão" idealizada; de outro, a possibilidade de exercitar a crítica "pela" razão. A Crítica da razão pura é a crítica ao conhecimento em geral, mas é também dialética/dilema: a certificação do estatuto da razão contra a naturalização e brutalização do pensamento e da ação humana (ZANOLLA, 2007).

Não se deve banalizar essa antinomia, correndo risco de cometer injustiças com Kant. Por mais que seu pensamento arrisque à abstração, sua intenção objetiva alcançar, de maneira inconformista e incansável, estágios de independência, autonomia e emancipação contra qualquer tipo de dominação ou ignorância. Daí a ideia da formação do sujeito cognoscível, 
passível de conhecer, ao tempo que também objeto, visando um ser cognoscente, que "conhece enquanto sujeito" (ADORNO, 1995a).

Isso identifica uma maneira peculiar, controversa e polêmica de ver o homem e pensar a sociedade, que gerou protestos, incompreensão e influenciou gerações posteriores de intelectuais, sobretudo, a teoria crítica frankfurtiana. Para compreender a influência do pensamento de Kant em temas acerca da educação e da subjetividade na teoria crítica, necessário se faz recorrer à concepção de formação cultural para dois pensadores clássicos, cujo pensamento atravessa os temas subjetividade e objetividade: Marx e Freud.

\section{MaRX E A EDUCAÇÃO: A FORMAÇÃO PELO TRABALHO}

Como se viu em Kant, analisar a educação pressupõe, a priori, estabelecer uma relação entre sujeito e objeto, teoria e prática (ADORNO, 1995a). Nesse sentido, analisa-se o pensamento marxiano como representante máximo da escola moderna do materialismo dialético, uma das principais fontes de pesquisa para compreender os processos formativos, sobretudo, no que diz respeito ao aspecto sócio-histórico que abrange as condições estruturais e objetivas em que se situa o sujeito contemporâneo. A educação em Marx reflete as relações produtivas permeadas pela constituição social, pelo trabaIho; de um lado, reflete a desumanização e alienação; de outro, a possibilidade de liberdade (MANACORDA, 2007). Isso postula uma dialética que emerge a práxis como categoria primordial, objeto transformador do pensar para a ação revolucionária; estética regida pela ontogênese do ser histórico e social.

Em Marx, o mundo sensível se coloca como motivação de crítica aos filósofos e aos riscos do pensamento abstrato, corroído pela inércia do idealismo e do conformismo. No lugar do sujeito cognoscente, Marx e Engels apresentam o ser genérico, fruto de relações antagônicas e da interação política e social. O valor da contribuição de Marx à teoria do conhecimento é inestimável; deixou um patrimônio intelectual em que para pensar a educação exige-se enxergar a formação do ponto de vista da organização perversa do sistema capitalista. Uma organização que tem o trabalho como instrumento eficaz da barbárie, mas que poderia encontrar alívio em uma ação universal, transformadora e consciente, através do redimensionamento do próprio trabalho (MANACORDA, 2007).

Essas ideias demonstram uma estética que encontra alívio na possibilidade de romper com a dominação e usufruir da arte como uma gratificação relativa ao trabalho alienante (MARX; ENGELS, 1993). Realizar atividades artísticas, fora da perspectiva do tempo livre administrado, seria uma alternativa em uma sociedade verdadeiramente comunista. 
Segundo Manacorda (2007), a educação em Marx visa investir em estruturas revolucionárias e históricas, objetivando uma formação para a criação na perspectiva de ver a si e ao outro, na contraposição ao pensar sensível acerca da realidade. Desse modo, o homem produz as modificações necessárias à sua formação, ao tempo que é modificado por essa. Assim, à educação caberia romper com a organização social resultante da alienação, representada por um homem coisificado e preso à sua condição natural, que visa unicamente à sobrevivência imediata.

Embora Marx não tenha se dedicado a estudos da psicologia e tenha criticado o mundo sensível do idealismo alemão, denunciou o universo objetivo alienante. Isso permitiu um olhar para a educação a partir da perspectiva materialista, ao tempo que exige olhar a educação a partir do universo subjetivo. Por coerência, acredita-se que seus estudos acerca da subjetividade, embora não mencionem estudos psicológicos, prenunciam essa necessidade (MARX, 1993). Por coerência, não é por acaso que Freud, criador da Psicanálise é uma referência importante para a teoria crítica.

\section{FREUD E A EDUCAÇÃO - A FORMAÇÃO COMO RENÚNCIA À BARBÁRIE INSTINTUAL}

Em certa medida, na perspectiva adorniana, pode-se afirmar que para Marx, o processo formativo do trabalho é permeado pelo processo formativo apresentado por Freud. Isso quando se reconhece, em Marx, uma preocupação com a humanização do ponto de vista da superação do fazer natural, em prol de um trabalho libertário e consciente; enquanto para Freud, o trabalho manifesta renúncia aos instintos humanos mais agressivos, capacidade de superação da natureza instintual, em prol da natureza social. O potencial sublimatório através da cultura e dos conflitos inerentes à conservação social envolve lidar com a transformação da natureza de si e do objeto, como trabalho (FREUD, 1973a). Uma interação conflituosa, instaurada pela própria natureza em termos humanos e sociais frente às exigências culturais, as quais possibilitam a sobrevivência tanto no aspecto coletivo quanto individual (KUPFER, 1995).

Freud pensa a educação do indivíduo como desdobramento da luta interna ambivalente entre pulsão e instinto, repressão e sublimação: vida/amor referindo-se a Eros, deus grego que representa o amor como possibilidade de impulso vital; por outro lado - em constante interação com este último - apresenta Tanatos, analogia ao deus grego da morte, referindose a processos primários inerentes à agressividade (FREUD, 1973a).

Na psicanálise, o pressuposto básico para pensar o sujeito da educação é considerá-lo como o ser da carência. A incompletude humana 
funda a ambivalência que gira, de maneira instintual, em torno da satisfação das necessidades, determinadas pelos instintos primários (autodestruição e morte); ou, de sua renúncia, elaboração que leva à consciência das contradições existentes entre o sujeito e o objeto, efeito que confronta a realidade frente aos impeditivos éticos em razão da vida social (autopreservação). Isso postula um pensamento que reconhece limites entre a constituição ideal do sujeito e as possibilidades formativas, advindas das exigências sociais. Em Freud, o problema da educação configura sua solução e contradição ao mesmo tempo: remete ao sujeito cognoscente como manifestação conflitante; mas, contraditoriamente, visa à vitória de Eros (vida) sobre Tanatos (morte), da cultura sobre a barbárie.

Nesse sentido, a educação não é um fim em si, mas um caminho para a humanização; o que não aplaca seu caráter dramático: não ser, seguramente, um caminho para esse nobre intento. Daí a polêmica referente ao fato de que Freud afirma não existir uma educação perfeitamente humana (KUPFER, 1995). Para o autor, a educação materializa a tensa relação entre a satisfação das necessidades (incluindo fantasias e idealizações da realidade) e os padrões societários exigidos ao homem considerado educado/civilizado; cenário de renúncia cultural à necessidade imediata, uma moeda de troca para uma boa convivência: um teste social para a aceitação mútua entre os homens. Isso exige um tanto de equilíbrio pela economia libidinal, ou melhor, manifesta a necessidade de trabalhar as frustrações cotidianas e seus limites como condição à preservação humana.

A sociedade estabelece uma espécie de contrato com o homem, o que implica renúncia à satisfação imediata: o sujeito abre mão do gozo momentâneo para ser reconhecido pelos seus pares como ser social passível de convivência. Isso não ocorre, de forma tranquila, no universo subjetivo; gera custos à psique (frustrações e perdas): o preço do reconhecimento ou do progresso civilizatório é a castração (FREUD, 1973a). A maneira como cada sujeito lida com os infortúnios da barganha, entre ser aceito e ser reprimido, resulta das condições objetivas e afetivas de concretização ou não da formação humana esperada. Essa discussão leva à compreensão de uma lacuna a ser preenchida na análise da subjetividade pela abordagem sócio-histórica.

Na perspectiva da teoria crítica, o sujeito da ação revolucionária é colocado em cheque, quando essa condição deixa escapar a relação entre elementos ontogenéticos e filogenéticos. A educação, amparada pela ótica freudiana, resulta de um sujeito idealizado pelas condições materiais de dominação; é um sujeito revestido por elementos múltiplos que agregam fatores, 
sociais, ambientais, genéticos, biológicos e históricos; ocorre, assim, um revés em termos metodológicos, teóricos e práticos, configurando a (de)formação como elemento possível e impossível ao mesmo tempo (ADORNO, 1973).

De imediato, o sujeito freudiano não é apreensível a priori; mas é um ser complexo que não se deixa captar de maneira dogmática, apenas pela ambígua relação linear entre teoria e prática. Exige, sim, pensar sua ambivalência em uma sociedade da ordem da necessidade antes do desejo, da fantasia e do pensamento permeando a razão e a noção de realidade. Essa possui, em sua dinâmica própria, elementos sociais e psíquicos de inversão de sentidos e valores, o que leva à frase: "O eu não é senhor de sua própria casa" (FREUD, 1973), dado que o comportamento humano não se revela necessariamente pela aparência das ações ou palavras, mas de uma interação complexa entre consciência e inconsciente. Fenômeno que atualiza a condição ambivalente e, não apenas isso, aponta para um processo dialético na dinâmica psíquica, remetendo à dicotomia entre neurose e perversão, capacidade de enfrentar as frustrações, ou a conciliação entre id, ego e superego, entre sujeito e objeto, selando o processo que leva à pseudoconsciência como uma manifestação da drástica indiferenciação humana pela cultura.

Dado que a cultura exige um sujeito reflexivo, crítico - ou seja, que confronta em seu íntimo, de maneira conflituosa, a possibilidade de satisfação imediata e a aceitação social -, nos termos psicanalíticos, pensar a educação em Freud inviabiliza idealizar processos formativos como elemento-chave da desbarbarização. Ao contrário, "modelar" um ser humano como perfeito, educado e puro arrisca celebrar o sujeito perverso, egocêntrico, narcisista, frio e prepotente em nome da educação idealizada, fetichizada (ZANOLLA, 2007).

A educação constitui obra humana como materialização da tensão entre agressividade e consciência, elaboração e inconsciência. Resulta de um processo constante e inacabado. A educação enquanto um método ou técnica ideal nunca finalizará respostas aos problemas humanos, porque, se isso se realizasse, a vida seria interrompida, mecanizada, previsível. Assim, de modo redundante, cabe ao ser humano tornar-se cada vez mais humano, lapidar-se, refletir sobre si e o outro constantemente, de maneira crítica, inconformista e corajosa, mesmo que para isso precise se autodesmistificar antes de desmistificar o outro.

O que para Freud (1973a) representa a possibilidade de romper gradualmente com processos alienantes e deformadores, constituem ao sujeito ações extremamente dolorosas e impensáveis (ex: autocrítica ou renúncia à autoidealização, ao prazer imediato). 
Para Adorno,

Em psicanálise estritamente, quem sabe do enfrentamento entre forças psíquicas pode, frente às existências pulsionais subjetivas, dar-lhe toda sua vigência à objetividade e, em especial, às leis do movimento econômico, muito mais que teorias que, só por estabelecer um contínuo entre sociedade e psiquè, renegam, do núcleo da teoria analítica, o conflito entre ego e o id. (ADORNO, 1955, p. 153)

O conflito entre id (fator externo) e ego (fator interno) é identificado como possibilidade de lidar com o universo subjetivo, de modo a não se submeter ao universo objetivo e, sim, se reconhecer em meio a esse. Para os frankfurtianos, não se trata de reinterpretar Marx e Freud ou de adaptá-los a uma teoria alternativa; antes, ampliar suas especificidades, ou o que de mais apropriado puder ser extraído desses autores para a apreensão do objeto pelo sujeito (ZANOLLA, 2007).

A relação da teoria crítica com a psicanálise demonstra que os frankfurtianos não estavam dispostos a abrir mão da crítica a qualquer conhecimento, seja ele oportuno ou não, do ponto de vista de seus interesses (ADORNO, 1995b). É o que se deduz quando a teoria crítica busca, na psicanálise, referências para a compreensão do contexto cultural e social, no sentido de aprofundar, ainda mais, a especificidade do seu objeto: "o sujeito subjetivado ao tempo que sem subjetividade". Ao contextualizar a psicanálise e seus fundamentos, suas contribuições em âmbito metodológico e suas contradições, pode-se entender melhor a posição da teoria crítica adorniana em relação à educação. Para a teoria crítica, nunca é demais lembrar que a positividade não é privilégio apenas da teoria positivista e conservadora ou da prática tecnicista; seus riscos são recorrentes em qualquer conhecimento estabelecido.

A psicanálise avançou sobre seus próprios objetivos e, além disso, possuía, com relação à psicologia, uma particularidade muito instigante, uma metodologia de caráter dialético - propositadamente ou não - como se percebe em Freud ao defender a autoria da psicanálise: "Pero habiendo reconocido hace ya mucho tiempo como destino inevitable del psicoanálisis el de excitar la contradicción y el disgusto de los hombres me he decidido a considerarme como el único autor responsable de sus caracteres fundamentales" (FREUD, 1973a, p. 1896).

A preocupação com a contradição da civilização - o progresso desumano -, ligada ao desenvolvimento técnico e às dificuldades para se domar os instintos agressivos, foi amplamente explorada no conjunto das obras de Adorno sobre a dominação social. Isso recorda a Freud (1973a), 
para quem "Toda historia de la civilización es una exposición de los caminos que emprenden los hombres para dominar sus deseos insatisfechos, según las exigencias de la realidad y las modificaciones en ella introducidas por los progresos técnicos" (p. 1864).

Além do caráter conflituoso e sociológico da psicanálise, outro elemento que mobiliza os críticos está relacionado à importância dada à memória como elemento condutor da regressão para se chegar à consciência. O alívio de traumas por parte do indivíduo só pode ser proporcionado, mesmo que de imediato, por meio da história pretérita, para se obter, assim, a consciência de suas neuroses.

En esta labor descubrimos aquel factor característico de los procesos psíquicos de las neurosis, al que luego di yo el nombre de regressión. Las asociaciones del enfermo retrocedían desde la escena que de aclarar se trataba a sucesos anteriores, y forcaban a nuestro análisis, encaminado a rectificar el presente, a ocuparse del pasado. [... ] Esta dirección regressiva llegó a constituir un importante carácter del analisis, pues se demonstró que el psicoanálisis no consguía explicar nada actual, sino refiriéndolo a algo pretérito, incluso que todo suceso patógeno supone outro anterior, que no siéndolo por sí mismo, presta dicho carácter al suceso ulterior. (FREUD, 1973a, p. 1897; grifos nossos)

Segundo Freud (1973c), é muito tentador para um psicanalista centrar nos conflitos humanos presentes em seu formato aparente, o que justifica seu esforço em estudar o indivíduo com base em lembranças de sua infância e não ceder a componentes meramente fisiológicos. Freud apresenta uma proposta polêmica e contraditória para os estudiosos do indivíduo e da cultura em a Etiologia das neuroses (1973c). Esse estudo, com base em experiências clínicas, demarca, de forma definitiva, a mudança do método catártico - e da tendência neuropsicológica - para a psicanálise, ou, como a denomina, Teoria da repressão/resistência, basilar no descobrimento da sexualidade infantil pela investigação do inconsciente: En un principio sólo se advirtió que era necesario referir al pasado el afecto de las impresiones actuales (1973c, p. 1901).

Destarte, a relação entre educação e psicanálise não poderia deixar à margem seu caráter filosófico. A filosofia, há milênios, se ocupa não apenas de temas relativos à psicologia como também de questões vinculadas ao tema da consciência. Embora seja uma ideia polêmica, para Freud (1973d), a importância do inconsciente para a psicologia delega-lhe o status de objeto (p. 1859). Assim, essa ciência amplia o conhecimento da filosofia, contribuindo para o progresso das ciências especiais, o que faz com que “El descubrimiento 
de las actividades anímicas inconscientes há de obligar muy especialmente a la filosofia a tomar su partido" (p. 1859).

Embora a psicanálise contribua também com a biologia, analisando instintos parciais - funcionamento de zonas erógenas -, a sexualidade amplia a visão acerca da libido, aparecendo como um tema mais abrangente, ligado à vida anímica do indivíduo.

Del mismo modo que en los posteriores estados de apetencia sexual no son meramente los órganos sexuales de la persona amada, sino todo su cuerpo, lo que se constituye en objeto sexual, resultan ser en el niño punto de origen de excitación sexual y de producción de placer sexual ante un estímulo adecuado, no sólo los genitales, sino también, otras distintas partes do soma. (FREUD, 1973d, p. 1861)

Segundo o autor, o interesse pela tendência sexual coincide com o da conservação da espécie e, assim, embora limitada, a biologia tem muito a contribuir com a psicanálise. A elaboração é crucial para compreender a formulação dos conceitos instinto de morte e pulsão de vida, ${ }^{1}$ e determina que a singularidade humana é cientificamente passível de generalização. Para Freud, a psicanálise estabelece uma mediação entre a Psicologia, a Antropologia e a Biologia. Essa polêmica retoma uma preocupação pertinente de Adorno: o perigo de se psicanalisar o indivíduo, utilizando o método freudiano, embora admita o lugar do fator biológico na definição da constituição humana (ADORNO, 1995a).

Não obstante, não se pode negar que produtos das fantasias, mitos, religiões, fábulas e crenças dos povos que constituem a humanidade permitem à psicanálise trazer à luz investigações pertinentes e apresentar hipóteses psicológicas em busca do conceito amplo de subjetividade. Como bem apresenta Freud (1973d), a comparação da infância do indivíduo com a história primitiva dos povos tem demonstrado, em amplo aspecto, ser muito frutífera, apesar de se tratar de uma aproximação apenas inicial da área antropológica com o método. Ao investigar sociedades consideradas primitivas, Freud percebe que a função capital do mecanismo psíquico é uma descarga das tensões geradas pela necessidade de sobrevivência e que, para isso, o homem precisa empreender uma luta que envolve fatores objetivos e subjetivos.

Presumem-se aspectos sociológicos da psicanálise como aproximados à teoría crítica entrecruzados à educação. Para Freud, "Toda la historia de la civilización es una exposición de los caminos que empreendem los hombres para dominar sus deseos insatisfechos, según las exigencias de la realidad" (FREUD, 1973d, p. 1864). Essa delimitação permite aos estudiosos da 
psicanálise aproveitar intensamente a rica relação dos fatores filogenéticos com a realidade social. Freud reconhece isso, quando afirma que o desaparecimento do fator social e o predomínio do fator sexual "convertem as soluções neuróticas em caricaturas inutilizáveis" para a resolução dos problemas do homem, acrescentando: "A psicanálise tem como objeto a psique individual, mas seu trabalho não pode abrir mão dos fundamentos efetivos da relação entre indivíduo e sociedade" (p. 1865).

Esses argumentos esclarecem os motivos que levam a psicanálise a encontrar, na área da estética, um importante instrumento de análise da cultura. Compreender a arte como manifestação material do trabalho é primordial, sobretudo para o entendimento do papel da sublimação como processo que se ocupa da renúncia aos desejos primários para o desenvolvimento da civilização. A arte pode representar, segundo Freud, transformações que acalmam desejos repulsivos: "Las fuerzas impulsoras del arte son aquellos mismos conflictos que conducen a otros individuos a la neurosis y han movido a la sociedad a la creación de sus instituciones" (p. 1865). A dinâmica do processo sublimatório, ou seja, dos mecanismos de controle dos instintos, via formação cultural, não poderia ser deixada de lado pela teoria crítica, ao analisar o binômio alienação x consciência. Por outro lado, o interesse pela pedagogia acrescenta, definitivamente, ampla capacidade de aproximação da psicanálise com o universo educacional (FREUD, 1973d). Nas palavras de Freud, a compreensão da relação entre a psicanálise e a educação, a partir do universo infantil até o adulto, permite ao pedagogo uma intervenção muito mais eficiente:

Cuando los educadores se hayan familiarizado con los resultados del psicoanálisis, le será más fácil reconciliarse con determinadas fases de la evolución infantil, y entre otras cosas, no correrán al peligro de exagerar la importancia de los impulsos instintivos perversos o asociales que el niño muestre". (FREUD, 1973d, p. 1866)

Assim, pode-se aferir que, na teoria crítica adorniana, a colaboração da psicanálise está situada na descoberta da administração da renúncia e no reconhecimento à repressão elaborada como fator relevante para a formação da personalidade. A neurose é encarada como central para desvelar o sujeito; esse situado entre a falta e a satisfação, tanto no que se refere ao limite e à autoridade, como da capacidade de afeto enquanto desdobramentos da repressão. Segundo Freud, os desvios da sublimação de seus fins primitivos podem ser, assim, dirigidos para outros mais valiosos. "Nuestras mejores 
virtudes han nacido, en calidad de reacciones y sublimaciones, sobre el terreno de las peores disposiciones" (p. 1867).

À parte disso, Adorno (1955) assevera que, em relação à identidade idealizada e mediada socialmente, a ideia do aparelho psíquico regido por uma dinâmica conflituosa que envolve aspectos ligados ao (in)consciente fez com que a possibilidade de tencionar as instâncias objetiva e subjetiva se tornasse mais real.

É digno de nota que a psicanálise freudiana tenha ganhado destaque nessa discussão, por desmistificar, de maneira fundamental, o ideal histórico de sujeito/homem; ideia que ressoa ao longo da construção da metodologia psicanalítica e, por consequência, desmascara a prática e o trabalho em todas as suas instâncias, inclusive, no espaço sagrado da educação. Imaginar que a agregação da psicanálise ao pensamento dialético-histórico se deve ao fato de que esse não deu conta da realidade - ou que, com isso, os problemas referentes à dominação ideológica seriam resolvidos - seria mais um tabu teórico a evitar. Com efeito, seria impensável à teoria crítica adorniana avistar a educação desprovida das contribuições de Kant, Marx e Freud. Se assim o fosse, emblematicamente, essa lacuna estaria em conceitos e categorias medulares aos estudos de Adorno como: preconceito, violência, formação, indiferenciação, autoridade, emancipação e, dominação.

\section{ADORNO E A EDUCAÇÃO - DILEMAS CULTURAIS IMANENTES À RELAÇÃO SUJEITO E OBJETO}

Inicialmente é preciso deixar claro que não existe uma cisão entre "duas teorias críticas em Adorno": uma que se refira à educação e outra à estética; como se a dita concepção adorniana de educação não envolvesse o espírito estético em seu arcabouço de formação (ZANOLLA, 2012).

O olhar estético sobre a teoria e a prática educacional em Adorno possui herança, sobretudo, kantiana, marxiana e freudiana: a educação reflete trabalho humano, passível de contradições; portanto, qualquer obra artística é objeto da atividade ligada à forma e ao conteúdo: exige percepção da tensa e complexa relação entre sujeito e objeto, teoria e prática, consciente e inconsciente, materialismo e idealismo, universal e particular (ADORNO, 1995a).

Não por acaso, como se viu, a educação em Adorno é permeada pela formação sociológica, filosófica, psicológica e estética. É digno de nota que tenha escrito obras sobre música, teatro, literatura, cinema, acrescentando aspectos sócio-históricos e culturais às análises. Em Adorno, constituem como 
objeto de trabalho temas como: arte, ciência, educação, sociedade, cultura, política e conhecimento. Sua tese primordial defende que essas atividades são dotadas de sentido na perspectiva da consciência - não apenas com base em Hegel, mas em também em Kant - de si, para si, em si, e além de si. Assim, o sentido da arte seria escandalizar, denunciar, sair do lugar comum, rasgar o véu do que está posto, indigente e objetificado, mediado de maneira vulgar (ADORNO, 1995a; HORKHEIMER; ADORNO, 1985).

A teoria adorniana visa construir novos conhecimentos sem com isso descartar o velho. Dinâmica que abarca ruptura e continuidade, epopeia dialética, não linear. O pensamento conservador deve ser retomado para ser negado, postulado para ser revisto e atualizado sem ser, com isso, empobrecido ou deturpado na sua origem. Conteúdo e forma, técnica e criação, essência e aparência constituem o novo, como um todo contraditório de velhas ações e pensamentos que envolvem as elaborações humanas atualizadas. Uma contingência da renúncia instintual depurada, atravessada pela sublimação através do trabalho reflete o sentido do belo na perspectiva clássica: o bem, o justo, possibilidade de humanização (PESSANHA, 1987).

Na perspectiva crítica, a não percepção da contradição arrisca a padronização e o preconceito, recorrência da barbárie; conciliação entre o universo objetivo e subjetivo que indiferencia e adoece sociedade e homem. A frieza e a alienação caminham de braços dados em uma sociedade patológica (ADORNO, 1995c). Sobre esse risco, importa enfrentar as contradições às últimas consequências: à reflexão cabe não se conformar e resistir, e dotar de sentido humano a formação.

Se existe uma função para a educação, essa se encontra na promoção da cultura com fins de humanização, no combate à barbárie em todas as suas nuances, no investimento ao pensamento crítico e autocrítico. Isso concretiza o princípio da emancipação, permite militar contra a ignorância, configurada enquanto violência de qualquer espécie. A barbárie é vista de maneira ampla e pensada como obstáculo à educação verdadeira: isso reclama enfrentar desafios inerentes à própria constituição do conhecimento filosófico e científico (HORKHEIMER; ADORNO, 1985).

A esse respeito, os parâmetros para a dialética negativa (ADORNO, 1984) concebem o conhecimento como trabalho infindável, inacabado, regido por forças internas e externas inerentes a esse, e dele constituinte. Isso exige o exercício de afirmação e negação do pensamento kantiano, da volta para o sujeito, o giro copernicano; proposta de Adorno que faz referência à necessidade de pensar o objeto da subjetividade na intenção de apreender o sujeito da objetividade (ADORNO, 1995a), dado que, o próprio 
sujeito - distanciado, ao tempo que aproximado do objeto - é a lente para se interpretar a sociedade. No século XVII, Galileu, recorrendo à empiria, foi apenas um dos pensadores que possibilitaram conexão e oposição entre teoria e prática, sujeito e objeto, materialismo e idealismo; aperfeiçoou a teoria heliocentrista, fato que, paradoxalmente, só pôde ser constatado após o aparecimento da teoria cosmológica: contínua e, ao mesmo tempo, inversa à de Copérnico, produzida no século anterior. Assim, enquanto o homem é a medida para o conhecimento, o conhecimento, por outro lado, constitui a medida para o homem. Esse dilema configura a antítese da relação entre materialismo e idealismo, ciência e filosofia, técnica e criação artística. Entre humanismo e empirismo, iluminismo e positivismo, não há abismo tão grande que não possa ser ultrapassado pelas contradições (a) dialéticas da teoria e da prática.

Enquanto patrimônio do conhecimento na perspectiva crítica, a educação condiciona uma chance ao pensamento livre que, embotado pela complexa teia da relação entre universal e particular, não desvincula a ferida narcísica que o persegue a partir de suas origens: a indiferença às próprias contradições. Celebra o eu epistêmico da objetificação humana na mais completa abstração (ADORNO, 1995a).

De fato, a educação pela perspectiva crítica frankfurtiana insere a luta contra o preconceito e a banalização da ignorância, efeito que leva à frieza e à crueldade humana. Cabe à educação resistir à irracionalidade invertida pelo ideal de razão. Como diria Adorno (1995a), não basta se apoiar na recorrente intenção recta, ou seja, na ilusão de que valores e conceitos definem o problema por completo, em si. Segundo o autor, se assim o fosse, perpetuaria a ingenuidade frente aos mecanismos culturais de dominação, situação a ser combatida pelo que denomina "intenção obliqua da intenção obliqua" (p. 181); uma experiência menos pragmática no trabalho, disposta ao novo e criativo.

Enfim, toda essa discussão remete à questão inicial acerca dos fatores culturais e educacionais que podem conferir ao homem estatuto de ser social, de modo que esse se reconheça e seja reconhecido como humano, como um sujeito da maioridade. À luz da teoria crítica, isso requer retomar, de forma exaustiva, a lição kantiana (KANT, 1996): a intenção de conhecer o consciente (ser cognoscente) e reconhecer o" a ser conhecido", o inconsciente (ser cognoscível). Quem sabe, assim, poderiam ser evitados prejuízos ao grandioso projeto sócio-histórico materialista? Uma vez que a incapacidade de discernir em que momento a liberdade concreta se anula e, ainda, na impossibilidade de tolerar a autocrítica, se obstaculizam experiências verdadeiramente possíveis pela educação emancipadora e autodesmistificadora. 


\section{EDUCATION AND PSYCHOANALYSIS IN ADORNO - THE APOLOGETIC (RE)VERSION OF CULTURE}

ABSTRACT: The aim of this paper is to analyze the complex relationship between Education and Psychanalysis in the light of Adorno's Critical Theory. The discussion is epistemologically based on the concepts of subject and object, materialism and idealism, subjectivity and objectivity. The proposal considers contributions of leading thinkers on the theory of knowledge, such as Kant, Marx and Freud at the interface with culture and education. The key concepts: critique, self-criticism, autonomy and humanization are presented as relevant to the discussion.

KEYwords: Education. Psychoanalysis. Critical theory. Adornian theory.

\section{EDUCACIÓN Y PSICOANÁLISIS SEGÚN ADORNO - LA (RE)VERSIÓN APOLOGÉTICA DE LA CULTURA}

Resumen: El objetivo de este estudio es analizar la compleja relación entre la Educación y el Psicoanálisis bajo la luz de la teoría crítica de Adorno. La discusión se guía epistemológicamente por los conceptos de sujeto y objeto, el materialismo y el idealismo, la subjetividad y la objetividad. La propuesta considera importantes contribuciones de importantes pensadores de la teoría del conocimiento, tales como Kant, Marx y Freud, en la interfaz con la cultura y la educación. Se consolida como la discusión pertinente al objeto de los conceptos claves: crítica, autocrítica, conciencia, la autonomía y humanización.

Palabras claves: Educación. Psicoanálisis. Teoría crítica. Teoría de Adorno.

\section{NOTA}

1. A definição de instintos pulsionais consta na obra O mal estar na cultura de Freud (1973a), edição espanhola recomendada pelo próprio autor. Nessa, na elaboração dos conceitos de pulsão e instinto, prevalece uma tensão inerente à constituição da libido. A libido não é apenas sexual; é sexualizada, o que possibilita pensar a tensão ou o conflito vida/morte, autopreservação/autodestruição e, sujeito/objeto. Conflito esse importante para a constituição da cultura. Dito isso, para Freud, a educação corresponde, necessariamente, às condições humanas oferecidas pela interação entre cultura e sociedade (ZANOLLA, 2010).

\section{REFERÊNCIAS}

ADORNO, T. W. De la relación entre Sociología y Psicologia. Actualidad de la filosofia. Barcelona/Buenos Aires: Paidós, 1955. (Coleção Pensamiento Contemporâneo). 
. Temas básicos de sociologia. São Paulo, Cultrix, 1973.

. Dialectica negativa. Madrid: Taurus, 1984.

. Sobre sujeito e objeto. Palavras e sinais - modelos críticos 2. Petrópolis:Vozes, 1995a.

. Notas marginais sobre teoria e práxis. Palavras e sinais-modelos críticos 2 . Petrópolis: Vozes, 1995b.

. Educação após Auschwitz. Palavras e sinais - modelos críticos 2. Petrópolis: Vozes, 1995 c.

. Educação e emancipação. Rio de Janeiro: Paz e Terra, 1999.

FREUD, S. El malestar en la cultura. Obras completas. Tomo III. Madrid: Biblioteca Nueva, 1973a.

. El metodo psicoanalitico de Freud - 1903-1904. Obras completas. Tomo I. Madrid: Biblioteca Nueva, 1973b.

. História del movimiento psicoanalitico - 1914. Obras completas. Tomo II. Madrid: Biblioteca Nueva, 1973c.

. Multiple interes del psicoanalisis - 1913. Obras completas. Tomo II. Madrid: Biblioteca Nueva, 1973d.

. Introduccion al narcisismo - 1914. Obras completas. Tomo II. Madrid: Biblioteca Nueva, 1973e.

HORKHEIMER, M.; ADORNO, T. W. Dialética do esclarecimento. Rio de Janeiro: Jorge Zahar, 1985.

KANT, I. Sobre a Pedagogia. Piracicaba, Editora UNIMEP, 1996.

. Crítica da razão pura. São Paulo: Martin Claret, 2003. Série Ouro.

KUPFER, M. C. Freud e a educação. São Paulo: Scipione, 1995.

MANACORDA, M. Marx e a pedagogia moderna. Campinas: Alínea, 2007.

MASSARO, G. Relações históricas entre pensamentos filosóficos e psiquismo. Revista de Psicologia Clínica, São Paulo: USP, v. IX, n. 3, set. 1980.

MARX, K. Manuscritos econômico-filosóficos de 1844. Trad. Maria Antonia Pacheco. Lisboa: Avante, 1993.

PASCAL, G. O pensamento de Kant. Trad. Raimundo Vier. Petrópolis: Vozes, 1999.

PESSANHA, J. A. Platão: vida e obra. São Paulo: Nova Cultural, 1987. p. VII- XXI. (Coleção Os Pensadores).

ZANOLLA, S. R. S. Teoria crítica e educação - considerações acerca do conceito de práxis. Revista Educ-Ativa, Goiânia, n. 1, p. 107-119, jan./jun. 2002. 
Teoria crítica e epistemologia: o método como conhecimento preliminar. Goiânia: PUC, 2007.

. Educação e barbárie: aspectos culturais da violência na perspectiva da teoria crítica da sociedade. Revista Sociedade e Cultura, Goiânia, UFG, v. 13, n. 1, p. 1415-1439, jul./ago. 2010.

. O conceito de mediação em Adorno e Vigotski. Psicologia e Sociedade, Belo Horizonte: UFMG; v. 24, jan./abr. 2012.

SílVIA Rosa dA SiLVA ZaNolla é doutora e pós-doutora em Psicologia Escolar e do Desenvolvimento Humano pela Universidade de São Paulo (USP); professora associada da graduação e da pós-graduação da Faculdade de Educação da Universidade Federal de Goiás (FE/UFG); pesquisadora com ênfase em psicologia social e educacional a partir da abordagem teórico crítica da Escola de Frankfurt; desenvolve estudos e pesquisas sobre indústria cultural; infância, educação ambiental, consumo e violência; concepção de infância em Adorno; jogos eletrônicos e formação de valores; metodologia e epistemologia.

E-mail: silviazanollaufg@hotmail.com 